\title{
A FORMAÇÃO DO PROFESSOR DE CIÊNCIAS E OS DESAFIOS DA PRÁTICA EM QUESTÕES SOCIOCIENTÍFICAS
}

\section{Science Teachers' Education and the Challenges of Practice with Socioscientific Issues}

\author{
José Roberto da Rocha Bernardo* \\ Pedro Guilherme Rocha dos Reis ${ }^{* *}$
}

\begin{abstract}
Resumo: A recomendação de inclusão de questões sociocientíficas nas aulas de ciências da educação básica ganhou força de política pública em diversos países do mundo. Nos Estados Unidos e na Inglaterra, onde os primeiros movimentos surgiram, as orientações introduziram modificações profundas na estrutura curricular. Em países de língua latina, como Brasil e Portugal, suas influências podem ser verificadas em documentos oficiais que constituem a base da Educação em Ciências. Em geral, as novas orientações trazem a esperança de mudanças no sentido de uma abordagem mais significativa dos conteúdos científicos e que explicite as relações que a ciência estabelece com questões próprias da contemporaneidade. Entretanto, a implementação dessas propostas tem sido vista como um desafio, sobretudo no que diz respeito às situações da escola e do professor, que precisam adequar suas práticas aos novos objetivos pedagógicos e curriculares. Este texto pretende discutir resistências e descompassos que estão envolvidos na implementação dessas propostas, sem abrir mão de apresentar as possibilidades que as questões sociocientíficas podem representar para o ensino de ciências e para a formação de professores. Para tal, buscaremos construir nossas reflexões a partir das seguintes questões: Quais são os limites e possibilidades em relação à inserção de questões sociocientíficas na educação básica? Por que as escolas e os professores resistem a essa perspectiva? É possível formar um professor para uma prática em questões sociocientíficas?
\end{abstract}

Palavras-chave: Questões sociocientíficas. Formação de professores. Educação em ciências.

\begin{abstract}
The recommendation to include social and scientific issues in basic education science classes has gained strength in public policy in several countries around the world. In the United States and England, where the first movements emerged, the guidelines introduced profound changes in the curriculum structure. In portuguese-speaking countries, such as Brazil and

\footnotetext{
* Graduação em Bacharelado em Física pela Universidade Federal do Rio de Janeiro-UFRJ (1988) e graduação em Licenciatura em Física pela Universidade Federal do Rio de Janeiro-UFRJ (2002). Mestrado em Engenharia Metalúrgica e de Materiais pela Coordenação dos Programas de Pós-Graduação em Engenharia-COPPE, da Universidade Federal do Rio de Janeiro-UFRJ (1998) e doutorado em Ensino em Biociências e Saúde no Instituto Oswaldo Cruz (2008). É professor do Departamento Sociedade, Educação e Conhecimento e subcoordenador do Programa de Pós-Graduação em Educação da Faculdade de Educação da Universidade Federal Fluminense-UFF. ORCID ID: https://orcid.org/0000-0003-3912-5786. E-mail: bernardo.jrr@gmail.com

** Graduação em Biologia pela Universidade de Lisboa (1988), Mestrado em Didática das Ciências pela Faculdade de Ciências da Universidade de Lisboa (1997) e Doutorado em Didática das Ciências pela Faculdade de Ciências da Universidade de Lisboa (2004). Professor Associado e Subdiretor do Instituto de Educação da Universidade de Lisboa. ORCID ID: https://orcid.org/0000-0002-9549-2516. E-mail: preis@ie.ulisboa.pt
} 
Portugal, their influences can be verified in official documents that form the basis of Science Education. In general, the new orientations bring the hope of changes towards a more meaningful approach to scientific content that makes explicit science relationships with contemporary issues. However, the implementation of these proposals has been seen as a challenge, especially regarding to the school and teacher situations, who needed to adapt their practices to the new pedagogical and curricular objectives. This text aims to discuss resistances and mismatches that are involved in the implementation of these proposals, without giving up the possibilities that the socioscientific issues can represent for science teaching and teachers' education. For such, we will build our reflections from the following questions: What are the limits and possibilities in relation to the insertion of socio-scientific issues in basic education? Why do schools and teachers resist this perspective? Is it possible to train a teacher for a practice in socioscientific issues?

Keywords: Socioscientific issues. Teachers' education. Science education.

\section{As questões sociocientíficas e as relações ciência-tecnologia-sociedade-ambiente}

As tensões que marcaram o período da Guerra Fria e da Corrida Espacial, bem como a lógica da competição que se estabeleceu no mundo contemporâneo, colocaram em evidência alguns aspectos controversos relacionados aos processos científico-tecnológicos. Assim, os incômodos provocados por alguns eventos que marcaram o século XX, como o episódio de Hiroshima, o lançamento do Sputnik e o uso indiscriminado de pesticidas na Agricultura, desencadearam um forte movimento no sentido da ciência e da tecnologia se pautarem por princípios éticos e morais e de um maior envolvimento dos cidadãos no controle desses empreendimentos.

No contexto educacional, esse movimento influenciou as políticas públicas voltadas à Educação em Ciências em diversos países. Dentre os elementos que levaram a mudanças na educação básica, podemos destacar a ampliação do número de interessados em ciências e o controle social sobre a ciência e a tecnologia e sobre as questões sociais e ambientais a elas relacionadas. A meta do letramento científico em larga escala, por exemplo, embora considerada um "mito" inalcançável por autores como Shamos (1995), ganhou destaque em documentos oficiais da Educação nos Estados Unidos (AAAS, 1993), com o objetivo claro de formar um maior número de cientistas. Inspirados pelas mesmas questões e demandas surgiram outros movimentos em todo o mundo como a abordagem ciência-tecnologia-sociedade (CTS) para o ensino de ciências, que propõe a introdução de discussões que envolvam as relações CTS nos currículos oficiais, e a abordagem ciência-tecnologia-sociedade-ambiente (CTSA), considerada por alguns autores como uma extensão da primeira com ênfase localizada na dimensão ambiental (AIKENHEAD, 2003).

A inserção de discussões sobre questões sociocientíficas (QSC) na sala de aula ganhou visibilidade como proposta a partir desses movimentos, e vem sendo recomendada nas últimas décadas por educadores e pesquisadores da área. Em geral, uma QSC se caracteriza como tema de reconhecida relevância social e caráter controverso (por exemplo, as aplicações da nanotecnologia) que facilita a abordagem dos conteúdos científicos propriamente ditos, aqueles regularmente introduzidos pelas disciplinas escolares, de forma articulada com outras dimensões - política, econômica, socioambiental, ética, moral e cultural - ligadas ao tema (BERNARDO, 2013). 
A gravidade das controvérsias sociocientíficas e socioambientais que afetam as sociedades torna imprescindível a capacitação dos cidadãos como: (1) a compreensão da rede intrincada de relações entre a ciência, a tecnologia, a sociedade e o ambiente e (2) as competências de cidadania ativa necessárias ao seu envolvimento na tomada de decisões democráticas e na ação sociopolítica no sentido da resolução destas problemáticas (REIS, 2009, 2013a, 2020).

Essa forma de aproximar os slogans CTS, CTSA e QSC representa uma visão que não é compartilhada por todos os autores. No que diz respeito à abordagem QSC, por exemplo, alguns estudiosos (SADLER, 2004; ZEIDLER et al., 2005) procuram diferenciá-la das demais destacando o seu potencial em relação às discussões que envolvem, sobretudo, aspectos éticos e morais. Entretanto, também não há consenso em relação a esta interpretação.

No que diz respeito às ações em sala de aula, devido ao seu caráter controverso, as QSC são vistas como catalisadoras de processos argumentativos (BERNARDO, 2013), o que as torna adequadas para o desenvolvimento de habilidades argumentativas junto aos estudantes (SADLER, 2004), aspecto considerado de grande relevância para a atividade de ensinoaprendizagem.

A diversidade de interpretações acerca do significado de cada um dos slogans pode ser verificada, por exemplo, em trabalhos como o de Aikenhead (1994). O autor se baseou, principalmente, na frequência, na ênfase e na forma como as relações que envolvem a tríade CTS foram introduzidas em documentos oficiais de diversos países, identificando uma ampla variedade de perspectivas curriculares que se apoiam nos pressupostos CTS. A abertura que caracteriza esses slogans, ainda que possa representar um problema de identidade em relação aos pressupostos e princípios que organizam as reflexões sobre esse campo do conhecimento, por outro lado, tem favorecido a sua permanente reconstrução e, consequentemente, a sobrevivência das suas propostas por mais de três décadas.

Do ponto de vista da organização curricular, muitas dessas propostas se caracterizam como abordagens temáticas.

\footnotetext{
Abordagem temática: perspectiva curricular cuja lógica de organização é estruturada com base em temas, com os quais são selecionados os conteúdos das disciplinas. Nessa abordagem, a conceituação científica da programação é subordinada ao tema. (DELIZOICOV; ANGOTTI; PERNAMBUCO, 2002, p. 189).
}

Propostas curriculares de inspiração temática se aproximam daquilo que Lopes (2008) denomina "currículo integrado" e abordam o tema a partir da articulação de diferentes disciplinas cujos conteúdos específicos orbitam em torno desse tema, que funciona como eixo estruturante no currículo.

Na seção a seguir vamos apresentar uma breve discussão sobre a inserção de QSC nos currículos dos ensinos básico e médio e a reação dos professores diante dos desafios que essa perspectiva de abordagem traz.

\section{O enfoque QSC nos contextos brasileiro e português: o currículo e a situação do professor}

Assim como em outras partes do mundo, tanto no Brasil quanto em Portugal, as abordagens baseadas nas QSC têm sofrido as esperadas recontextualizações em função das 
condições locais e sua influência sobre as políticas públicas desses países é marcante. No caso brasileiro, por exemplo, esta se verifica a partir da década de 1990, com a publicação dos Parâmetros Curriculares Nacionais para o ensino médio - PCN (BRASIL, 1999) e mais recentemente nas Diretrizes Curriculares Nacionais da Educação Básica - DCN (BRASIL, 2013) e na recém homologada Base Nacional Comum Curricular - BCNN (BRASIL, 2017). Além disso, seus princípios e pressupostos encontram-se presentes também nas matrizes que fundamentam o Exame Nacional do Ensino Médio (ENEM) e nos últimos editais do Programa Nacional do Livro Didático (PNLD), por exemplo. Em Portugal, os currículos de ciências publicados há duas décadas (PORTUGAL, 2001) apelam à discussão explícita de QSC como forma de promover uma alfabetização científica composta por um conjunto articulado de conhecimentos (substantivos, processuais e epistemológicos), capacidades de raciocínio e de comunicação e atitudes e valores. De acordo com esses documentos, essa alfabetização científica é decisiva na capacitação dos cidadãos para um envolvimento ativo em processos decisórios relacionados com propostas científicas e tecnológicas. Também as Aprendizagens Essenciais para o 3. ${ }^{\circ}$ Ciclo do Ensino Básico, relativas à área disciplinar de Ciências Naturais, propõem que se valorizem as controvérsias sociais em torno de aplicações científicas e/ou tecnológicas (PORTUGAL, 2018).

Contudo, a implementação dessas orientações e desses programas tem sido carregada de tensões e descompassos. Embora os documentos tragam expectativas de mudanças em relação às práticas nas escolas, estas nem sempre ocorrem em função da dificuldade de realização, sobretudo quando se trata de proposta de grande alcance, como é o caso daquelas que têm como objetivo a substituição do currículo convencional (GALVÃO et al., 2017; GALVÃO; REIS; FREIRE, 2011). Ao entrarem em disputa com a cultura escolar (FORQUIN, 1993) e com o currículo disciplinar estabilizado (GOODSON, 1997), essas propostas de caráter interdisciplinar geralmente encontram resistência por parte dos professores e da própria escola como um todo. Segundo Lopes (2008):

\footnotetext{
O atual discurso em defesa do currículo integrado, nas definições curriculares oficiais e no pensamento curricular, não implica a superação das disciplinas escolares ou mesmo a diminuição de seu poder na seleção e na organização do conhecimento escolar (LOPES, 2008, p.82).
}

Lopes afirma que a maioria das pesquisas desenvolvidas por analistas de currículos no Brasil encara essas propostas "como pacotes de ideias discrepantes e, por conseguinte, sujeitas a múltiplas ressignificações, o que ocasiona uma implementação distorcida" (LOPES, 2008, p. 83). Além disso, outras causas são apontadas nas pesquisas, como a má formação dos professores, o que os torna "incapazes de dar conta das propostas estabelecidas". Nesse caso, uma interpretação que transfere a responsabilidade para os professores e para os cursos de formação das universidades.

Essas interpretações, segundo Lopes (2008), se apoiam em modelos de análise que mantém separadas políticas e práticas curriculares. A esse respeito, a autora propõe um novo modelo que não esteja apoiado na lógica da verticalidade e da hierarquização para interpretar a relação entre os textos curriculares oficiais e a prática.

A prática não é apenas uma caixa de ressonância das definições oficiais, tampouco é um espaço autônomo que constrói sentidos para o currículo a despeito das ações governamentais. $\mathrm{O}$ contexto da prática se constitui, efetivamente, como produtor de 
sentidos para as políticas de currículo, ressignificando definições curriculares oficiais e vendo suas práticas e textos serem ressignificados por essas mesmas definições (LOPES, 2008, p. 84).

Atribuir exclusivamente à formação do professor as dificuldades que envolvem a inserção de QSC em sala de aula certamente seria uma forma reducionista de enxergar a complexidade desse processo. Entretanto, é fato que a formação da maioria dos professores que se encontram em atividade no Brasil ocorreu dentro de uma lógica organizacional disciplinar, e a necessidade de deslocamento em direção a uma prática baseada na interdisciplinaridade que caracteriza essas propostas pode provocar uma sensação de desempoderamento no professor em relação à posição de especialista na sua disciplina (FORQUIN, 1993) e como desdobramento, uma resistência desses profissionais aos currículos integrados (LOPES, 2008).

Outro aspecto da formação docente a ser considerado se apresenta em função da natureza controversa das QSC. A introdução desses temas em sala de aula demanda do professor a competência para mediar situações de argumentação, sem a qual toda a riqueza do debate sobre o tema pode se perder.

A lógica que media a formação docente é a mesma que prevalece nos currículos regularmente praticados nas escolas, onde a disciplina escolar faz valer a sua força no papel de organizadora do currículo (CHERVEL, 1990). Dialogando com Tardif (2002) diríamos que esses professores mobilizam em suas ações saberes - disciplinares, curriculares, da formação profissional, e experienciais - construídos a partir da mesma lógica disciplinar, o que pode influenciar a prática desses profissionais.

É imperativo considerar também em nossa discussão o papel do professor como elaborador de estratégias e táticas (CERTEAU, 2011) que se materializam a partir não só daquilo que é previsível, mas também da imprevisibilidade que caracteriza o contexto escolar, produzindo novos significados para o currículo. Contudo, não se pode esperar que este professor promovesse mudanças audaciosas na estrutura organizacional do currículo, tendo como referência no seu processo de formação profissional a lógica da compartimentação em disciplinas.

Além disso, as concepções presentes nos documentos oficiais brasileiros não atentam para a possibilidade de ressignificação e de construção do currículo na ação, ignorando o papel do professor nesse processo, ainda que sem uma intencionalidade explícita, como se a figura do professor pudesse ser apagada, o que concorre ainda mais para os descompassos em relação à implementação dessas propostas de longo alcance que objetivam substituir o currículo tradicionalmente praticado (GALVÃO; REIS; FREIRE, 2011).

Em Portugal, a análise cruzada de vários estudos de caso (desenvolvidos e publicados durante a última década, no âmbito de uma linha de pesquisa e intervenção destinada a apoiar a discussão de QSC em sala de aula) mostra que a realização bem sucedida desse tipo de prática educativa está fortemente associada com as concepções dos professores sobre: a) a relevância educacional dessas atividades; b) a educação em ciência; c) o currículo; e d) a cidadania (REIS, 2013b). Para além de reconhecerem grandes potencialidades educativas nesse tipo de atividade, esses professores assumem-se como construtores de currículo, exercendo o poder de adaptarem os tópicos curriculares e escolherem as experiências educacionais de acordo com o que consideram serem as necessidades da sociedade, as características específicas dos alunos e os contextos únicos em que vivem. Dessa forma, opõem-se a uma concepção restrita de currículo como catálogo de termos, fatos e teorias que os alunos devem memorizar de forma exaustiva e repetir em testes. Simultaneamente, esses professores compartilham a concepção de que as 
crianças e os jovens são cidadãos de pleno direito, e não apenas objetos de socialização. Logo, estão particularmente empenhados em estimular o envolvimento dos seus alunos em ações sociais e ambientais. Neste estudo, constatou-se ainda que a implementação dessas atividades não é exclusiva dos professores que têm mais experiência de ensino, dependendo fortemente das concepções dos professores e dos conhecimentos necessários para a sua concepção, gestão e avaliação.

\section{Possibilidades em relação à perspectiva QSC}

Nas seções anteriores foram discutidos aspectos relacionados com os limites e descompassos que envolvem a inserção das QSC na educação básica, bem como a situação dos professores diante dos desafios que essas questões representam.

Não é nosso objetivo aqui aprofundar a discussão acerca das possíveis diferenças entre os slogans apresentados. Entretanto, um dos aspectos relacionados à abordagem QSC que pode ajudar a minimizar os descompassos aos quais Lopes (2008) se refere é o fato de que nessa perspectiva não parece haver intenção de promover mudanças profundas no currículo regular, ficando seus objetivos limitados a inserções pontuais nos espaços que são possíveis dentro do currículo. Com isso, os efeitos provocados pelo choque com a cultura escolar e as ameaças de desempoderamento do professor e da disciplina escolar são atenuadas, já que não há necessidade de renúncia à organização curricular centrada nas disciplinas escolares, o que nos leva a acreditar na perspectiva QSC como oportunidade real de inserção dos estudantes em debates que podem se materializar na escola, pois sabemos que no Brasil, por exemplo, não contamos com instituições comprometidas em promover essas discussões junto à sociedade.

O grupo de pesquisa Currículo, Docência \& Cultura (CDC), do Programa de Pósgraduação em Educação, da Universidade Federal Fluminense, vem realizando ações articuladas de pesquisa, ensino e extensão, que visam contribuir para essa discussão. São ações que se materializam, principalmente, a partir da valorização da parceria escola-universidade.

De acordo com Foerste (2005), a parceria é fundamental para a formação dos professores e refere-se a

[...] relações entre diferentes sujeitos e instituições (governo, universidade, escolas, sindicatos, profissionais de ensino em geral etc.) que passam a estabelecer interações para tratar de interesses comuns, construindo e implementando programas a partir de objetivos compartilhados [...] (FOERSTE, 2005, p. 37).

Com as parcerias acreditamos ser possível diminuir as distâncias entre as duas instituições, dando voz à escola e aos seus atores, na busca por uma relação de horizontalidade que possa contribuir para minimizar os descompassos apontados por Lopes (2008) no que diz respeito à inserção das QSC nas salas de aula.

A dinâmica das parcerias possibilita a formação de grupos de trabalho que podem envolver professores da universidade, professores experientes da educação básica, estudantes dos cursos de pós-graduação de mestrado e doutorado, além de futuros professores (estudantes dos cursos de licenciatura em Biologia, Física e Química). A partir dos grupos realizam-se estudos teóricos, planejamentos de estratégias de ensino e desenvolvimento de material didático compatíveis com a perspectiva QSC, que finalmente são inseridos como atividades nas salas de aula das escolas parceiras pelos professores experientes (coautores das propostas). A 
implementação das propostas é acompanhada por outros membros do grupo de trabalho na condição de alunos de prática de ensino (estudantes de licenciatura em formação) e pesquisadores (estudantes de mestrado, doutorado ou professores da universidade). Assim, os grupos de trabalho se caracterizam como espaços privilegiados para formação docente dentro do seu espaço de atuação por contribuir para o desenvolvimento profissional do professor experiente e para o fortalecimento da sua autonomia (BERNARDO, 2008), ao mesmo tempo em que promovem a formação inicial dos licenciandos num processo de construção da formação com vários intervenientes (SELLES; SALOMÃO, 2008).

No que diz respeito à pesquisa, as parcerias possibilitam estudos que colocam em foco vários quesitos, a saber: os limites, desafios e possibilidades que a perspectiva QSC encontra no contexto escolar, especialmente em relação ao currículo instituído; os processos formativos que as ações do grupo de trabalho podem desencadear e como estes processos ocorrem; as produções discursivas que ganham materialidade nas ações de planejamento desenvolvidas pelo grupo ou na forma de sequências de ensino e material didático de apoio; os processos argumentativos que se estabelecem nas salas de aula das escolas parceiras ou em cursos de formação (inicial ou continuada) de professores.

As ações desenvolvidas pelo CDC em relação aos estudos sobre as QSC em geral se articulam com atividades de formação em que os temas controversos têm papel central. Os temas são escolhidos a partir de diferentes motivações, podendo ser temas globais que se encontram presentes com frequência nos noticiários, ou locais, cuja relevância se verifica para um contexto geográfico específico. Como resultados das ações do grupo, destacamos os trabalhos de monografia de conclusão de curso de graduação e as dissertações de mestrado que se desenvolvem no contexto dessas ações, onde as discussões sobre diversos temas estiveram presentes, dentre eles o uso das técnicas de irradiação de alimentos na indústria, o caso do Acidente de Goiânia e os usos das radiações na medicina para fins diagnósticos e terapêuticos, os casos dos Acidentes de Fukushima e Chernobyl e o uso de usinas nucleares para a produção de energia elétrica, o debate sobre a natureza do aquecimento global - antropogênico ou não e a presença da ThyssenKrupp Companhia Siderúrgica do Atlântico (TKCSA) no bairro de Santa Cruz, na cidade do Rio de Janeiro, para a produção de aço.

Estudos realizados em Portugal (REIS, 2014, 2016; REIS; GALVÃO; BAPTISTA, 2018) têm evidenciado as fortes potencialidades de comunidades de prática no combate aos sentimentos de isolamento e desânimo dos professores que inibem a inovação em sala de aula. Essas comunidades de prática são formadas por professores, de todos os níveis de ensino e de vários países (Angola, Brasil, Cabo Verde, Colômbia, Espanha, Portugal), com interesses comuns e envolvidos num processo de construção coletiva, implementação e estudo de atividades e metodologias que visam apoiar os alunos em iniciativas informadas e negociadas sobre questões sociocientíficas e socioambientais. A grande maioria desses professores está ou já esteve envolvida em programas de mestrado e/ou doutorado Instituto de Educação da Universidade de Lisboa, possuindo experiência em pesquisa educacional. Trata-se de comunidades sem uma hierarquia definida e na qual as lideranças emergem espontaneamente em função do problema que se enfrenta e das competências de cada membro da comunidade. Perante as dificuldades sentidas por um elemento da comunidade no envolvimento dos seus alunos na realização de ações sociopolíticas sobre uma questão sociocientífica ou socioambiental, os elementos da comunidade mobilizam-se, de acordo com o seus interesses pessoais, disponibilidade e competências, no apoio a esse colega. Logo, não se trata de uma comunidade liderada/controlada por pesquisadores/professores do ensino superior. Qualquer um dos seus elementos pode apoiar colegas de qualquer outro nível de ensino, tudo dependendo das suas competências para fazer face a determinada dificuldade. Assim, já houve situações em 
que professores do ensino básico e/ou do ensino secundário apoiaram colegas do ensino universitário na realização de iniciativas de ação sociopolítica com recurso a redes sociais e a outras ferramentas da Web 2.0 e, outras situações em que colegas do ensino superior apoiaram professores do ensino básico e/ou do ensino secundário na definição de estratégias de avaliação de competências específicas dos alunos durante a realização das ações coletivas sobre questões sociocientíficas ou socioambientais.

Qualquer professor é livre de integrar uma destas comunidades de prática, bastando para tal que partilhe um forte interesse na discussão e na ação sociopolítica sobre questões sociocientíficas e socioambientais e uma forte crença na escola como força de desenvolvimento individual e de transformação social. Muitos membros desta comunidade acabam por utilizar as iniciativas de pesquisa-ação que realizam no âmbito destas comunidades para a concretização de projetos de mestrado, doutorado ou pós-doutorado. Uma dimensão importante das comunidades está relacionada com o empoderamento dos seus membros como investigadores através: a) da investigação sobre as suas próprias práticas; b) da apresentação de comunicações em congressos; c) da redação e publicação de artigos de investigação em revistas científicas e em revistas profissionais.

As comunidades de prática realizam reuniões presenciais - no Instituto de Educação da Universidade de Lisboa e em várias escolas dos professores participantes - e através de videoconferência - com colegas de outros países - com o objetivo de se desenvolver uma visão partilhada para o projeto. Nestas reuniões, partilham-se e discutem-se ações realizadas por elementos da comunidade - com o objetivo de desenvolver o nível de competência da comunidade e estimular os menos experientes à realização de iniciativas de ação sociopolítica sobre questões sociocientíficas e socioambientais - apoiam-se iniciativas em curso e procedese ao panejamento de novas ações. Uma atenção especial no conhecimento pedagógico pretende contribuir para a capacitação dos novos membros, ajudando-os a evitar ou superar alguns obstáculos normalmente associados a este tipo de projeto. Ocasionalmente, alguns dos membros da comunidade participam nas atividades de sala de aula dos seus colegas, exemplificando determinado tipo de práticas ou apenas observando e discutindo com o objetivo de apoiarem o desenvolvimento das competências e da confiança dos seus colegas. As diferentes interações realizadas, fortalecem os laços entre os membros e a identidade da comunidade através da acumulação de experiências, histórias, materiais e estratégias de sala de aula.

Todas as ações apoiadas no âmbito desta comunidade são negociadas coletivamente entre cada participante da equipa e seus alunos de forma a centrarem-se em questões sociocientíficas ou socioambientais reais (de âmbito local, nacional e/ou internacional) que os alunos consideram socialmente relevantes. Cabe aos professores assegurarem (através de negociação com os alunos) que a problemática escolhida se adequa ao projeto educativo da escola e ao currículo da(s) disciplina(s) envolvida(s).

Estas comunidades de prática - formadas por professores com interesses comuns e envolvidos num processo de construção coletiva, implementação e estudo de atividades e metodologias que visam apoiar os alunos em iniciativas informadas e negociadas sobre questões sociocientíficas e socioambientais - proporcionam uma "rede de segurança", apoiando-os durante seus esforços de inovação e permitindo a partilha de sucessos e a diluição e atenuação de fracassos. O envolvimento neste tipo de comunidade de prática proporciona: a) a compreensão de como a ciência, a tecnologia, a sociedade e o ambiente interagem; b) visões sobre como a sociedade deve funcionar; e c) o poder, a vontade e as oportunidades para transformar a sala de aula, a escola e a sociedade (ESPAÑA-RAMOS; REIS, 2017; REIS, 2014, 2016; REIS; GALVÃO; BAPTISTA, 2018; REIS; TINOCA; BAPTISTA; LINHARES, 2020). 


\section{Considerações finais}

Vimos que a inserção de controvérsias sociocientíficas nas aulas de ciências apresenta descompassos em relação à implementação dessas propostas. Dentre os problemas apontados destacam-se a diversidade de significados que o enfoque QSC pode admitir e as inevitáveis dificuldades entre a perspectiva integradora do currículo e a lógica organizacional baseada na compartimentação do currículo em disciplinas que é regularmente praticada nas escolas sob a influência da força da disciplina escolar (CHERVEL, 1990). Por outro lado, essa forma de abordagem pode significar oportunidade de conscientização sobre as relações complexas que a ciência estabelece com a contemporaneidade, sobretudo quando a inserção dessas questões ocorre a partir de objetivos de curto alcance em termos curriculares - sem a ambição de promover transformações profundas no currículo vigente centrado em disciplinas escolares.

A esse respeito, embora o enfoque QSC represente uma proposta que entra em disputa com o currículo disciplinar estabilizado (GOODSON, 1997), acreditamos que a sua articulação com a cultura escolar (FORQUIN, 1993) possa ocorrer por meio de inserções pontuais no currículo evitando assim, os descompassos apontados por Lopes (2008).

No que diz respeito à formação do professor, as disputas se estabelecem apoiadas nas mesmas forças antagônicas. De um lado a demanda por ações interdisciplinares que caracterizam o enfoque QSC e do outro a prática e a formação do professor, também construídas sob a lógica da organização curricular centrada em disciplinas. São fatores que podem provocar sensações de desempoderamento no professor, sobretudo em relação à sua posição de especialista em uma disciplina.

Outro aspecto a ser destacado é a dificuldade que o professor apresenta diante de situações que demandam a mediação de episódios argumentativos, situações frequentes em sala de aula quando se estabelecem os debates envolvendo as controvérsias que caracterizam as QSC.

Professores são agentes que ressignificam os programas oficiais, mobilizam saberes próprios (TARDIF, 2002) e elaboram estratégias e táticas (CERTEAU, 2011), mas sua prática é marcada pela compartimentação em disciplinas. Portanto, embora o processo educacional tenha a sua culminância na sala de aula e sob a regência do professor, não se pode esperar que essas mudanças ocorram exclusivamente por conta desse profissional. Assim, torna-se imprescindível que todo planejamento de atividades que envolvam QSC seja acompanhado de reflexões que focalizem aspectos da formação dos professores.

Não temos aqui a pretensão de ser prescritivos em relação à formação de professores. Entretanto, consideramos que a parceria escola-universidade, nomeadamente sob a forma de comunidades de prática, pode ser uma perspectiva promissora não só em relação ao desenvolvimento de atividades centradas em QSC como em relação ao desenvolvimento pessoal e profissional de todos os envolvidos. Ações de parceria deslocam as relações de poder em direção a uma maior horizontalidade entre a escola e a universidade, o que facilita consideravelmente a prática do trabalho colaborativo e a necessária troca de experiências que contribui para a formação de todos os envolvidos (estudantes de licenciatura, estudantes de mestrado e doutorado, professores das escolas e professores da universidade), tornando-os sujeitos ativos no processo de construção da própria formação e desenvolvimento profissional. 


\section{Referências}

AIHENHEAD, G. What is STS science teaching? In: SOLOMON, J. et al. (Orgs.). STS Education: international perspectives on reform. New York: Teachers College Press, p. 4759, 1994.

AIKENHEAD, G. STS Education: a rose by any other name. In: CROSS, R. (Ed.). A vision for science education: responding to the work of Peter J. Fensham. New York: Routledge Falmer, 2003, p. 59-75.

AMERICAN ASSOCIATION FOR THE ADVANCEMENT OF SCIENCE (AAAS). Benchmarks for science literacy. New York: Oxford University Press, 1993.

BERNARDO, J. R. R. Limites e possibilidades para a abordagem de questões sociocientíficas: a visão do professor de física da educação básica. Enseñanza de las Ciencias, v. extra (1), p. 376-380, 2013.

BERNARDO, J. R. R. A construção de estratégias para abordagem do tema energia à luz do enfoque Ciência-Tecnologia-Sociedade (CTS) junto a professores de física do ensino médio. 2008. Tese (Doutorado em Ensino em Biociências e Saúde) - Instituto Oswaldo Cruz, FIOCRUZ, 2008.

BRASIL. Ministério da Educação. Parâmetros Curriculares Nacionais: Ensino Médio. Brasília: MEC/SEF, 1999.

BRASIL. Ministério da Educação. Diretrizes Curriculares Nacionais da Educação Básica. Brasília: MEC/SEF, 2103.

BRASIL. Ministério da Educação. Base Nacional Comum Curricular. Brasília: MEC/SEF, 2017.

CERTEAU, M. A invenção do cotidiano. Artes do fazer. Petrópolis: Vozes, 2009.

CHERVEL, A. História das disciplinas escolares: reflexões sobre um campo de pesquisa. Teoria \& Educação, n.3, p.188-229, 1990.

DELIZOICOV, D.; ANGOTTI, J. A.; PERNAMBUCO, M. M. Ensino de ciências: fundamentos e métodos. São Paulo: Cortez, 2003.

ESPAÑA-RAMOS, E.; REIS, P. El proyecto We Act como marco para formar ciudadanos competentes a través del activismo colectivo basado en la investigación. Enseñanza de las Ciencias, $n^{\circ}$ extraordinario, p. 657-661, 2017. Disponível em: <https://ddd.uab.cat/record/184580?ln=ca>, Acesso em: 29 fev. 2020.

FOERSTE, E. Parceira na formação de professores. São Paulo: Cortez, 2005.

FORQUIN, J. Escola e cultura: as bases sociais e epistemológicas do conhecimento escolar. Porto Alegre: Artes Médicas, 1993. 
GALVÃO, C.; FREIRE, S.; FARIA, C.; BAPTISTA, M.; REIS, P. Avaliação do currículo das ciências físicas e naturais: percursos e interpretações. Lisboa: Instituto de Educação, Universidade de Lisboa, 2017.

GALVÃO, C.; REIS, P.; FREIRE, S. A discussão de controvérsias sociocientíficas na formação de professores. Ciência \& Educação, v.17, n.3, p. 505-522, 2011.

GOODSON, I. A construção social do currículo. Lisboa: EDUCA, 1997.

LOPES, A. C. Políticas de integração curricular. Rio de Janeiro: EdUERJ, 2008.

REIS, P. Ciência e controvérsia. Revista de Estudos Universitários, v.35, n.2, p. 9-15, 2009. Disponível em: <http://periodicos.uniso.br/index.php/reu/article/viewFile/559/273>, Acesso em: 29 fev. 2020.

PORTUGAL. Ministério da Educação. Programa de biologia e geologia para os $10^{\circ}$ e $11^{\circ}$ anos do curso geral de ciências naturais. Lisboa: ME, 2001.

PORTUGAL. Ministério da Educação. Aprendizagens Essenciais: Ensino Básico. Lisboa: ME, 2018.

REIS, P. Da discussão à ação sócio-política sobre controvérsias sócio-científicas: uma questão de cidadania. Ensino de Ciências e Tecnologia em Revista, v.3, n.1, p. 1-10, 2013 a.

Disponível em: <http://srvapp2s.urisan.tche.br/seer/index.php/encitec/article/view/1028/498>, Acesso em: 29 fev. 2020.

REIS, P. Factors of success regarding classroom discussions of SSI: a cross-case study. Les Dossiers des Sciences de l'Éducation, n.29, p. 67-80, 2013b.

REIS, P. Promoting students' collective socio-scientific activism: Teacher's perspectives. In: ALSOP, S. et al. (Orgs.). Activism in science and technology education. London: Springer, 2014, p. 547-574.

REIS, P. O papel das comunidades de prática na formação do desenvolvimento profissional de professores e do diálogo entre a escola e a universidade. In GENOVESE, L. G. R. et al. (Orgs.). Diálogo entre as múltiplas perspectivas na pesquisa em Ensino de física. São Paulo: Editora Livraria da Física, 2016, p. 173-194.

REIS, P. Environmental Citizenship \& Youth Activism. In: HADJICHAMBIS, A. Ch. et al. (Orgs.). Conceptualizing Environmental Citizenship for 21st Century Education. Series "Environmental discourses in Science Education". Cham: Springer, 2020, p. 139-148. Disponível em: <https://link.springer.com/content/pdf/10.1007\%2F978-3-030-202491_9.pdf>, Acesso em: 29 fev. 2020.

REIS, P.; GALVÃO, C.; BAPTISTA, M. Formação contínua de professores e comunidades de prática: perspectivas da Universidade de Lisboa. In: CACHAPUZ, A. F. et al. (Orgs.). Formação inicial e continuada de professores de ciências: o que se pesquisa no Brasil, Portugal e Espanha. São Paulo: Edições Hipótese, 2018, p. 257-275. 
REIS, P.; TINOCA, L. A avaliação do impacto do projeto "We Act" nas percepções dos alunos acerca das suas competências de ação sociopolítica. Revista Brasileira de Ensino de Ciência e Tecnologia, v.11, n.2, p. 214-231, 2018. Disponível em: < https://periodicos. utfpr.edu.br/rbect/article/view/8435>, Acesso em: 29 fev. 2020.

REIS, P.; TINOCA, L.; BAPTISTA, M.; LINHARES, E. The Impact of Student-Curated Exhibitions about Socio-Scientific Issues on Students' Perceptions regarding their Competences and the Science Classes. Sustainability, v.12, p. 2796, 2020. Disponível em: <https://www.mdpi.com/2071-1050/12/7/2796/pdf>, Acesso em: 12 abril. 2020.

SADLER, T. D. Informal reasoning regarding socio-scientific issues: a critical review of research. Journal of Research in Science Teaching, v.41, n.5, p. 513-536, 2004.

SELLES, S. L. E.; SALOMÃO, S. R. Formar professores de biologia e ciências naturais: uma obra a seis mãos. In: FERNANDES, N. S. M. et al. (Orgs.). Formação de professores: projetos, experiências e diálogos em construção. Niterói: EdUFF, 2008.

SHAMOS, M. H. The myth of scientific literacy. New Jersey: Rutgers University Press, 1995.

TARDIF, M. Saberes docentes e formação profissional. Petrópolis: Vozes, 2002.

ZEIDLER, D.; SADLER, T.; SIMMONS, M.; HOWES, E. Beyond STS: a research- based framework for socio-scientific issues education. Science Education, n.89, p. 357-377, 2005.

Recebido em dezembro de 2019.

Aprovado em maio de 2020. 